\title{
Linguistic Constructions and the Development of Theatre in Uganda
}

\author{
Michael Muhumuza
}

Makerere University Department of Performing Arts and Film P. O. Box 7062 Kampala Uganda, Momo Centre for Talent Development P. O. Box 27964 Kampala, Uganda

DOI: 10.36348/sijll.2021.v04i01.001

| Received: 03.10.2020 | Accepted: 14.10.2020 | Published: 11.01.2021

*Corresponding author: Michael Muhumuza

\section{Abstract}

This article looks at how linguistic constructions influenced development of theatre in Uganda. It traces the relationship between the constructions, conceptualization, theory and practice of theatre in Uganda. The article avers that linguistic constructions led to negative perceptions, which led to apathy towards theatre and inhibited Ugandan theatre scholars and practitioners towards adequate theatre conceptualisation, study and practice. The inhibition curtailed development of appropriate approaches to theatre, vis-à-vis ability to recognise artistic value and capability to organise theatrical elements into a good theatre experience, which led to inadequate development of theatre theory, skills, techniques and practice. The article proposes an approach that can help build capacity of theatre practitioners and scholars for appropriate exploitation of the Performing Arts and feed into the government's efforts of promoting the Creative Arts Industry (CAI) for employment creation, improved social intelligence and sustainable development.

Keywords: Uganda, Conceptualisation, Theory, Practice, Study, Theatre.

Copyright () 2021 The Author(s): This is an open-access article distributed under the terms of the Creative Commons Attribution 4.0 International License (CC BY-NC 4.0) which permits unrestricted use, distribution, and reproduction in any medium for non-commercial use provided the original author and source are credited.

\section{INTRODUCTION}

Prior to the advent of colonial rule, theatrical activities in Uganda were ubiquitous, highly regarded as an integral social activity, spontaneous and permeated a person's life cycle from pre-conception to life after death. It consisted of 'integrated artistic forms consisting of music, dance, drama, games, stories, embedded in marriage ceremonies, initiation rites, death rites, among others [1-6].

The performances celebrated achievements of the tribe in general and kings and chiefs in particular and criticised infallible powers of kings and chiefs, through artists' ingenious, spontaneous compositions and performances [2]. Achievements, fears, anxieties and other aspects of life as well as issues of the kingdom or clan were also portrayed. Topics and themes of performances varied with prevailing circumstances. The topics ranged from celebration to anxieties and fears and struggle for survival. Performances under this category served a threefold purpose. At one time they would be, for example, a celebration of successes attained at battle lines and appraisal of the heroes involved, and at times satirical and cynical for mistakes committed, while at other times appeasement for the gods [1].
After colonial take over, the colonialists dominated the natives by infiltrating the social, educational, religious, cultural, political and economic spheres. Considering natives 'archaic, lacking in style and associated with Satanism and wrong behaviour' [1, $8-10,2]$, they introduced new sets of goals and values that minimised traditional popular art forms like orature, music, dance, drama, poetry, storytelling, dressings, traditional worship, and traditional rites and ceremonies. They swept aside old values, culture, knowledge, belief systems and authorities; including the authority of the traditional rulers $[1,11]$ and were forced to adapt a western lifestyle encompassing ways of worship, writing, expression and performance [1, 12$15]$.

The new governance introduced new performance modes, new performance spaces and generated new linguistic constructions of theatre [1].

\section{METHODS OF RESEARCH}

A qualitative approach was used to depict how linguistic constructions had influenced the development of theatre in Uganda in terms of conceptualisation, theory and practice [6]. Data was collected using questionnaires, interviews, focus group interviews, participatory observation and documentary analysis and analysed according to Neuman's typology [16] and 
Miles and Huberman [17]. Analysis involved data preparation, counting and grouping, reduction, organisation and, relating, predicting, approximation, illustration, comparison, agreement and interpretation following selected themes. The researcher also provided quotations, where applicable, so as to capture salient issues in the findings. Data derived was sorted according to themes and presented in summary and descriptive prose.

\section{FINDINGS}

Findings of the study indicated that linguistic constructions of theatre were coalesced by the colonisation phenomenon which generated cognitive dissonance processes [3] on how theatre functioned and its different rendering [18]. Constructions such as Katemba/Ddikuula (funny, buffoonery, clowning clown, jester), munakatemba/Kapere (incongruous actor/actress), kuzanyilila/Kazanyilizi labazannyil Emizaanyo/ emizaano/ emizaanho, (player/ pretender/ time waster games/playing/), Mugoma (drummer/drama), playing/passing time, and Musilu Ddala Ddala, (very stupid) [1, 8-10, 9, 20, 4, 21] were identified and their impact on conceptualization, theory and practice of theatre in Uganda discussed.

\section{DISCUSSION}

\section{Impact of Linguistic Constructions on Conceptualisation of Theatre in Uganda}

Though with differences in ethnic origin, all terms used to refer to theatre in Ugandan local languages were derogative. Derogative statements were frequent when people behaved in a funny way or seemed out of order of normal behaviour. One cited example involved the speaker of the seventh parliament of Uganda, admonishing one of the members of parliament for alleging that the speaker had been involved in Kisanja [ $\left.{ }^{1}\right]$ money that parliament was a serious institution and if the member wanted Katemba, he could go and join Bakayimbira $\left[^{2}\right]$ at Pride Theatre.

Theatre practice is riddled with misconceived concepts such as Katemba (Theatre), Kuzannya (acting/performing/playing/pretending), Kusesa abantu (comic relief versus comedy), Kutambula ku 'siteegi' (stage movement versus walking around the stage), kukwatagana n'abalabi (creation of rapport with the audience versus exhibitionism), Kuyiyiz'awo

\footnotetext{
${ }^{1}$ The 1995 Uganda constitution used to restrict presidential terms to only two with each term consisting of five years. Towards the end of President Museveni's $2^{\text {nd }}$ elective term in 2001 there was a constitutional amendment process, which among other issues, sought to open the presidential term limits. The effort was commonly interpreted as president Museveni's effort to secure a third term commonly referred to as Kisanja.
}

\footnotetext{
${ }^{2}$ Bakayimbira is one of the oldest contemporary theatre groups in Uganda.
}

(improvisation versus extemporisation), Kuwulirwa (projection versus shouting), amaanyi (physical energy versus emotional energy) Kujjayo Ky'ozannya (externalisation versus overacting/exaggeration) and kulabibwa bulungyi (the $4^{\text {th }}$ wall versus the gallery) [1].

Even many theatre practitioners are not happy with the names given to theatre. Rather, the perceptions of the linguistic constructions of theatre are based on stereotypes particularly those associated with Kapere farcical skits [1]. Kapere was a naïve, comical and ludicrous character constructed by the Social Welfare Department of the colonial government to appeal to the audience by doing everything upside down. Construction of the character aimed at facilitating the use of theatre for development communication by appealing to the audience [4]. For example, a married dramatist who was also a director of a theatre company and an FM Radio comedian acknowledged that when he met people on the street, they thought he was comical all the time. As an actor, people thought he lived the life of an actor all the time to the extent that when he was moving on streets, people mimicked him [10].

Most theatre practitioners in Uganda use improvisation. However, as a concept and an art form, improvisation requires the performer to convey personality, and physical traits, conflicts and desires, and age and dress with minimum number of aids', [22, 23]. The performer must be trained to be able to master the art of theatre production, either by study or apprenticeship [23]. It involves understanding of different components of a production, like plotting, play making, acting, awareness of the environment/setting and basics on directing. Improvisation also demands 'physical and mental control, adaptability, acceptance of and positive response to criticism, directability and cooperation with others' [23]. Knowledge of the art of improvisation enables creativity to stay within the limits of theatre production development.

However, in Uganda theatre practice 'improvisation' is taken to mean yiiyiz'awo [1]. Theatre practitioners are at liberty to create impromptu situations and businesses on stage because of the misconception of improvisation [4]. Hence, many productions are extemporisations taken for improvisations. What appears on stage is made at the spar of the moment, sometimes the moments accounting for more than $50 \%$ of the entire production. Negative effects of spontaneous inclusions are seen when incidents, which occur during productions become subjects in the production $[1,4]$.

The actor also engages in 'repetition, simplification, exaggeration, rhythmic action, and transformation of natural sequences of behaviour into composed sequences'. He also achieves 'succession and contrast of scenes, harmony and clash of music, of dialogue, action implied', and the 'physical opposition 
of the characters. This enables the actor's intelligence to pass 'all these means in review, connecting them, fixing them in his memory to re-employ them at pleasure in succeeding representations [24].

Although theatre encompasses various disciplines like literature, social sciences, languages, fine art and designing and sciences relating to sound, lighting, and architecture, among others [25, 23, 26], people in Uganda still do not understand its multidisciplinary nature but merely derogatively regarded. The stereotypical and experimental modes of theatre do not represent the myriad of established theatre forms, expressions and opportunities that occur in theatres and constitute theatre studies. Experiences of theatre (as spectators, participants and scholars) are limited to manifestations of theatre in different theatrical encounters with insufficient knowledge on the discipline and craft of theatre.

Integration of concept based theatre practice still has a long way to go because of lack of a critical mass to espouse conceptually and practically proficient enough to articulate best theatre practices to theatre managers and hence could not positively influence approach to theatre practice in the different theatre groups. Conceptualisation of theatre among different stake holders of the theatre industry hence need to be redefined from a theatrical conceptual perspective in order to guide good theatre practice and study. The redefinition could range from appropriate naming of theatre to clarification on theatre concepts in order to positively influence theory and practice.

\section{Impact of Linguistic Constructions on Theatre Practice in Uganda}

Linguistic constructions of theatre are responsible for the poor state of theatre practice in Uganda that practices based on conceptual considerations are spitefully considered. Hence, linguistic constructions have influenced approaches to rehearsals and production dynamics, which have in turn, impacted on approaches to acting and directing, leading to inadequate productions.

Theatre practice is stereotypically perceived derogatively across all the communities as Katembal Kapere, Ddikuula, Kwedhangula, eby'emizaanyo/ eby'emizaan(h) kuzanyilila, or Musilu Ddala ddala. Hence, many of those who join theatre practice $\left[{ }^{3}\right]$ take it as has been constructed. Theatre therefore continually engages people who do not appreciate the relationship between theories and concepts of theatre and theatre practice and that are least motivated to salvage it or

\footnotetext{
${ }^{3}$ Discussion was held on 26/09/05 in ALR 5, Makerere University with third year students while acknowledging the poor state of theatre practice indicated that it was not easy to change the status quo.
}

those that are not aware of good theatre practice, methods and approaches.

Consequently, most theatre productions in Uganda are experimental in both form and content, 'shabby in structure and shambling in action' [24]. Playwrights and producers still lack essentials of artistic creativity. Most directors and performers miss runthrough themes and through lines to keep run-through action and point of emphasis. Actors have poor communication and characterisation techniques, are inconsistent, unbelievable, unimaginative and poor at handling contact scenes. Theatre artists cannot easily explore the essence of theatrical activity and are still being ruled by the desire for popularity without distinguishing themselves in production styles [1].

Conceptual and theoretical deepening of a production depends on adequate rehearsals. This enables a piece of art to appear as a seemingly life experience with due variations and placement of emphasis. Rehearsals enable performers to produce harmony of colour, sound and form in the performance, to master the technicalities of the theatre craft and to become familiar with the structure, rhythm and soul of the performance. Rehearsals also help performers to constantly cultivate perceptions of life and of all the other arts of painting, music, and sculpture [1]. They also promote accumulation of intelligence and preserve all creations of sensibility. Yet many theatre producers in Uganda do not know how to conduct complete rehearsal processes. The inadequacy leads directors to settle for any add-on/ins from the cast as conditions dictate. Inadequacy in handling rehearsal processes is revealed through disorganised stage business, inadequate and inappropriate articulation, and poor interaction among performers, inappropriate performeraudience relationship, inadequate production and performance techniques, and poor standards of performance.

Poor handling of the rehearsal process affects performers' capacity to adequately fit into the roles of the characters being enacted [23, 10, 94, 14, 9, 24]. As a result many actors are often in and out of character and unable to attain and sustain the essence and energy of their roles. Having been removed from the realm of cultural experience and social environments through colonial acculturation and alienation and dominantly employing people of low status, both directors and performers are not able to communicate remote lessons embedded in some plays.

Productions therefore become bigger than producers and performers can competently handle [1]. This is majorly because directors and performers do not have adequate knowledge on production and performance processes and production techniques [27]. They are also not conversant with different production orientations and production management processes. 
Many of them are not aware of the demands of proportionality, balance and harmony among designs. They only exploit opportunities to impress the audience through costumes, props and setting and artistic exaggerations [28]. Hence, instead of teaching the actors to 'act' the roles of the characters, they teach actors to 'do' the situation, which leaves them out of control of productions.

Most Ugandan directors use typecasting method, which look for actors with attributes nearest to the attributes of the role. However, with inadequate knowledge on directing, they default on blocking [27]. The purpose of blocking is to 'display the actors to the audience in meaningful patterns of arrangement and movement... and must be preceded by a clear definition of the relationship ...between the actors and the audience' [29]. However, many rehearsal processes neglect blocking and leave the actors to determine their stage business.

The aspect of motivated movement is always done mechanically, sometimes action coming after the word or as an immediate realisation of the demands of the dialogue. There are a number of cases where actors show that they are not conversant with principles of stage movement. Many productions consist of unmotivated movements yet, stage movement require motivation. Action on the other hand is taken to emphasise physicality and energy rather than inner action. Stage imbalances are also common indicating inadequate knowledge on principles of stage balance, focus, status, emphasis, visibility, and spacing, among others. Many performers are not aware of the need to maintain stage equilibrium on stage through appropriate usage of stage spaces.

Performers use indigenous elements of form like story, songs, music, instrumentation, dance, recitations and narration of local stories indigenous to the area to bridge gaps where dramatic dialogue could not sufficiently communicate. Some theatre productions are integrated with music, dance and dialogue, spiced with drumming and dancing. Singing is loosely connected in play structures but still the 'play' appears more 'musical' than dramatic as the playwrights claim. In some productions, groups just parch up items like traditional dances, folk music and sometimes recorded music by the group as a performance for their audience. In some cases groups have queen dancers who are on many occasions dressed scantly and gyrate with sexually provocative movements. However, though music and dance are usually predominant in these productions, they appear peripheral rather than integrated parts of the play and work more to explain setting and aid change of scenes rather than qualifying the plays as musicals.
Cases identified in this category included situations of scenes where characters enter a situation, say a few lines and start singing. Sometimes the music is sung with minimal internalisation of the situation, sometimes it is of differing generations and of differing cultures, which would have required differences in approaches to the situation. Cases of inappropriate or inadequate directing include; inappropriate articulation, inappropriate punctuation, inappropriate intonation, misplaced or no emphasis on issues, excess mannerisms and unnecessary anticipation in respect to speaking and listening, gestures clashing with dialogue, lack specificity in actions, performers speaking lines in stage descriptions as dialogue in situations that involve prompting, rushed speech and shouting [26]. Sometimes performers fail to pick cues and also fail to get involved in the inner action of the play and wait for their turn to perform and wonder around the stage trying to make sense of their presence.

Line delivery is another big problem. Performers are not aware that every line in a play expresses a different thought and so can be delivered appropriately [26]. Performers need to learn to listen, and to become involved in inner actions and moments throughout their presence on stage, to concentrate and to concern themselves with use of words in respect to pace, tempo and pitch, and make sense of the meaning of the words being spoken.

There is usually limited regard for depth of character, to trace its latent motives, to feel depth of emotions, to comprehend thoughts that are hidden under the words and a search of through-lines and through-action, among others. Hence, many actors miss the essence of their roles because they never find the 'spirits' of the roles. In such circumstances they could have come out with stronger characterisation, but most of them end up 'playing the characters' through caricature and not 'creating the roles' $[33,31]$.

There is mechanical acting, poor designing, poor stage management, poor directing and stereotyping, among others. Performers are limited in technique and skill [26] and show inadequacy in performance dynamics necessary for establishment of a theatre illusion, a basis for good theatre practice. Hence, many plays are in their raw form of development, and examine content of little significance. In essence, theatre practice in Uganda is still predominantly amateur. Many theatre directors and theatre managers lack theatre skills and technique and possess inadequate knowledge on issues being presented leading to gambling and lack of originality. Practitioners have inadequate awareness on what constitute discipline in the theatre arts. 'Many amateurs have no conception of the art of the theatre and are content to dabble on its fringes' [32]. 
Whereas many performances need more guidance from directors, this is not forthcoming. There is almost no consideration for most of backstage etiquette. Members of the cast do not keep time; and never observe basics of backstage etiquette like keeping silent and not hosting visitors backstage, and inadequacy in handling backstage business, props, furniture and costumes. Most artists in Uganda do not consider the director's guidance as final. According to actors, the director's control of the production process limits actors' creativity and makes them slaves to the text. In some case actors do not take lines of texts as they were written important to get; rather, they go for the idea in the lines and reserve freedom for creativity. In some of the performances performers flaunt the stage to charming effect with a round of vivacious, inhibitionfree entertainment capping the production. As a result there is always last-minute efforts in many performances to 'get some drama into the story' stemming from a last minute realisation that 'little literal truths are not dramatic' [33].

Approaches to theatre by selected theatre groups shows that practices are based on inadequate grounding in literary and performance techniques. There is need to begin agitating for development for theatre other than theatre for development. There are only isolated cases of fair directing and production techniques resulting in good stories, good plotting, movement, and action. In such cases the directors have formal study of theatre arts or have apprenticeship in theatre practice and are serious with the rehearsal process and sticking to business while on rehearsals. Therefore, for performing arts to improve, an effort has to be made by the performing artists and scholars. They need to enhance their picture through organisation, study and research on best practices in the performing arts, which shall enhance their conceptualisation of performing arts and improve practice, infrastructure, institutions, departments, programmes, profiles and portfolios in the performing arts.

\section{Impact of Linguistic Constructions on Study of Theatre Arts in Uganda}

Whereas study is basic in development of theory and practice of disciplines [34-36, 6, 33], in Uganda the study of Performing Arts is not popular [37]. The disciplines and practices of music, dance and drama were simplified as mere play and lacking in constructive consequence. Efforts to study theatre arts are regarded with contempt; hence, scholarly output Performing Arts is still at a very low level [1, 28, 27].

Even when institutions like the department of Music Dance and Drama (Now Performing Arts and Film) begun teaching theatre studies, conceptual clarity and practical expediency in crafts of theatre production and skills and techniques of performance theatre arts are still elusive $[1,28]$. Programmes of study available at the department of Performing Arts and Film (PAF) are congested and provide limited opportunities for practical exposure during the course of study.

Apathy towards study of theatre has been mainly because of discouragement from parents, local politicians, teachers and peers by the nomenclatures attached to Performing Arts studies. These de-motivate intending applicants through exposure to ridicule and yet they are not prestigious do not offer formal employment opportunities and honourable job profiles [1]. Instead students go for programmes or courses that are expected boost their social profile as graduates.

There have also been a lot of discouragements from society and parents that tried to dissuade the youths from studying the Performing Arts courses. They are oblivious of the fact that theatre is multidisciplinary, encompassing creative writing, literary studies, playwriting, directing, acting, costume, make-up, scenery, lighting, properties, theatre architecture, machinery, special effects, management, audiences, and criticism as well as the relationship of the theatre to society and culture in which it appears [25].

Lack of prestige for Performing Arts programmes and courses among students is based on negative perceptions of theatre by parents, peers and the people in the villages. People in Uganda believe that theatre art programmes are not engaging academically and consider studies in Performing Arts as more practical than theoretical. Most students admitted to offer a BA Drama programme and course used it to access admission and later change to other preferred programmes and courses $\left[{ }^{4}\right]$. Hence, there were also many candidates offering Drama as a subject in first year and dropped it massively at second year. Also, although there is a strong practice of theatre performances in schools there was still apathy towards study of theatre arts. Apathy (towards study of theatre arts) was revealed through many people in Uganda do not wish to follow up their practice of theatre with more academic study.

Linguistic constructions caused apathy towards study of theatre even by typical ordinary people. In one incident an uncle to a student who had been offered Drama at Makerere University, exclaimed to his mother that '...eh! Mutabani waawe agenzere kukora ebyadiikuula...!' (Meaning: so, your son has

\footnotetext{
${ }^{4}$ Discussion was held on $28 / 09 / 05$ in CIT LR 2, Makerere University with first year students who felt very bad that they had been admitted for a B Drama programme. The students were contemplating to change the programme or even try another University for other programmes. After the discussion they felt good and continued with the programme.
} 
gone to the university to study clowning!). Another student was advised by an uncle to stop wasting time and money going to study drama, which some people mistake for drummer (omugoma) but to go and learn theatre arts from master performers [1]. Despite the students' involvement in MDD activities at secondary school level there was widespread apathy towards study of theatre.

Apathy to study theatre meant that most people in Uganda practice theatre without studying it, which attitude bears negatively on development of theatre theory and practice $[29,38]$. Consequently, most of the theatre group leaders, producers, playwrights and performers have acquired rudimentary skills and techniques as teachers' in-charge of entertainment in primary schools or teachers of literature in secondary schools, while others depended on talent for theatre practice. People believe that getting involved in performances is okay as long as they are not classified as study programmes or courses [28].

Non-theatre University students get involved in performance activities for an annual cultural gala at Makerere University with gusto and participate actively, sometimes more accurately with authentic techniques of performance, but continue ridiculing MDD programmes and courses and students offering theatre studies as time wasters [1]. The main reason for apathy toward study of performing arts is the perception that they are not subjects for study but extra-curricular activities whose skill and technique are accessible through master artists and not academics [39, 19, 28].

Hence, through the 1940s, 50s and 60s, apart from Music, they remained co-curricular activities in primary and secondary schools and not examinable subjects. The nearest drama came to being an examinable subject was at the level of plays as part of the literature syllabus. But even then, the plays have been considered as literature and not theatre. Even at university level, theatre remained an activity for enthusiasts [22] until 1972 when the department of MDD now PAF was established. However, even after the establishment of the department there has been little scholarly output. From 1972 to 1997 the Department of MDD produced less than $200 \mathrm{BA}$ (A) graduates with MDD as one of the subjects between 1972 and 1996 and less than 500 combined graduates from the BA Drama, BA Music and BA Dance between 1997 to-date [1].

At post graduate level only 11 persons graduated with MA in MDD, (6 for Drama option and 5 for Music) MA in Music, Dance and Drama from 1972 to $2004\left[^{5}\right]$ when the programme was renamed MA in

\footnotetext{
${ }^{5}$ MA Graduates from MDD Department from 1972 to 2007 include: Joan Kamanyi -Drama (1978), Jessica Atwooki Kaahwa-Drama (1994), Sylvia Nanyonga -
}

Performing Arts. 7 others (3 for Music, 3 for Dance and 1 for Drama) and $1 \mathrm{PhD}$ have graduated between 2006 to date $\left[{ }^{6}, 1\right]$. Whereas there are other MA, Doctorate and $\mathrm{PhD}$ graduates from other universities, they remain too few to impact on professional theatre study and practice. The other programme on offer was a diploma in MDD (now Performing Arts and Film-DPAF) which had produced a sizable number of graduates. However, whereas there are many MDD diploma graduates, they cannot be expected to further conceptual and development of theatre conceptualization, theory and practice because the teaching on a diploma programme emphasizes practical skill enhancement rather than theoretical and conceptual exposition. It is therefore difficult to find adequate scholarly work in the areas of theory, criticism and practice on Uganda theatre.

Accordingly, although many students participate in performances while in secondary schools, they are not enthusiastic to enrol for studies in Theatre Arts. Whereas many people enjoy acting, get famous on account of their involvement in MDD activities at school and learn lessons out of themes and situations in activities they get involved in, they do not think of sitting in class to study Theatre Arts, which many even mistake for drummer (mugoma). Even master artists who would help in orientation of the young generation in good theatre practices, especially where study of theatre is still low is inadequate with most of the practitioners having no specialised experience other than just performing $[27,28]$.

\section{CONCLUSION}

The article indicated that linguistic constructions of theatre led to poor conceptualisation, practice and study. It presented and discussed the impact of linguistic constructions on theatre practice, showing that the constructions were responsible for the poor state of theatre practice in Uganda. The article further averred that linguistic constructions of theatre greatly influenced approaches to rehearsals and production dynamics, which then, impacted on approaches to acting and directing, leading to inadequacy of theatre productions study. The article

Music (1995), Dan Isiko Kisense-Drama (1995), Stephen Kasamba (1996), Patrick Kirumira-Drama (1997), Michael Muhumuza-Drama (2000), Kaskon Mindoti-Music (2001), Sarah Justine Kamya-SoziMusic (2002), Jackson Kamuntu-Music (2003), Hamidah Namugga-Drama (2005).

\footnotetext{
${ }^{6}$ The seven other MA and $\mathrm{PhD}$ graduates from MDD now PAF from 2006 to date include: Charles Lwanga, Nicholas Sempijja and David Basoga all in Music (2007), Kenneth Bamuturaki -Drama (2008), Alfa Daniels Mabingo the first MA Dance graduate in 2011, Eric Jemba Lutaaya -Dance (2014), Judith LubegaTusiime-Dance (2015) and Michael Muhumuza, PhD (2015).
} 
also argued that the linguistic constructions of theatre led to apathy greatly influencing approaches to rehearsals and production dynamics, which, then, impacted on approaches to acting and directing leading to inadequacy of theatre productions. The article recommends a 'concept-learning' and 'conceptteaching' model of education as an approach that can help build capacity among different stakeholders and lead to appropriate exploitation of the Performing Arts for employment creation and sustainable development.

\section{RECOMMENDATION}

For Uganda theatre to improve there is need for development of a 'concept-learning' and 'conceptteaching' model of education [40-42] where 'craftsmen' and 'artists' shall help theatre practitioners to understand different concepts in theatre before inclusively taking them up (Assisi, http:// htmlgear. tripod. con/ text/). The model shall enable development of capacity to teach CAPEs, improve foundational skills in the Performing Arts and enhance conceptual clarity of the performing arts. These shall then improve study of theatre as a discipline and professional theatre practice [23, 26, 43]. The model will increase opportunities to teach theatre notions like 'playing of objectives and action in the context of psychological naturalism, or political solitude' [44], and improve on establishment of details of theatre production and performance. The model shall also empower Performing Arts teachers and artists and scholars with performing Arts skills, techniques, methodology and knowledge to be able to impact the CPA industry all over Uganda.

\section{REFERENCES}

1. Muhumuza, M. (2014). Perceptions of Theatre in Uganda: Impact on theory and practice (Doctoral dissertation, Makerere University).

2. Kaahwa, J. A. (2004). Ugandan Theatre: paradigm shifts. South African Theatre Journal, 18(1), 82111.

3. Harmon-Jones, E. E., \& Mills, J. E. (1999). Cognitive dissonance: Progress on a pivotal theory in social psychology. In Scientific Conferences Program, 1997, U Texas, Arlington, TX, US; This volume is based on papers presented at a 2-day conference at the University of Texas at Arlington, winter 1997.. American Psychological Association.

4. Mbowa, R. (2000). 'Luganda Theatre and its Audience' in Uganda: A Cultural Landscape. (Reprint) Kampala, Fountain Publishers, 204-223.

5. Mpuuga, W. (1987). Amagezi g'Ab'edda. Kisubi: Marianum Press.

6. Bukenya, A. (1984). The Bride. Nairobi: EAPH.

7. Low, D.A. (1964)."The Advent of Populism in Buganda". Comparative Studies in Society and History, 6(4); 433-443.

8. Simwogerere, A. (2016). Oral Interview on "Conceptualisation, Practice and Study of Theatre in Uganda", held at Bat Valley Theatre on $28^{\text {th }}$ August 2016.

9. Mukiibi, A. (2016). Oral Interview on "Conceptualisation, Practice and Study of Theatre in Uganda", held at Bat Valley Theatre on $28^{\text {th }}$ August 2016.

10. Lubwama, K. (2016). Oral Interview on "Conceptualisation, Practice and Study of Theatre in Uganda", held at Bat Valley Theatre on $28^{\text {th }}$ August 2016.

11. Césaire, A. (1989). Discourse on Colonialism (Discours sur le Colonialisme). Paris: Présence Africaine.

12. Kishani, B. T. (2004). "Ideologies of Women's Names among the Nso' of Cameroon: A Contribution to the Philosophy of Naming, Decolonization and Gender". An African Journal of Philosophy, 18(1-2).

13. Fagan, P. (2001). "Time for Instruction in the Three W's". Family and Marriage and Religion and Civil Society. The Heritage Foundation.

14. Macpherson, M. (2000). "Makerere: The Place for Early Sunrise", in Eckhard Breitinger. (Ed.) Uganda: A Cultural Landscape. Kampala: Fountain Publishers, 23-36.

15. Ngugi Wa Thiong'o. (2009). The River Between. Nairobi: EAPH.

16. Neuman, W. R., \& Neuman, W. R. (1991). The future of the mass audience. Cambridge University Press.

17. Miles, M. B., \& Huberman, A. M. (1984). Drawing valid meaning from qualitative data: Toward a shared craft. Educational researcher, 13(5), 20-30.

18. Morey, E. (2006). 'Preferences, Perceptions, Choices, and the Unconscious, but not Freud', Working Draft, Colorado: Colorado University.

19. Ocwinyo, J. (2002). Footprints of the Stranger, Kampala: Fountain Publishers.

20. Mirembe, M. Ntangaare. (2000). Theatre and the Market in Uganda, Unpublished $\mathrm{PhD}$ Thesis, and Kampala: Makakere University.

21. Kasule, S. (1998). 'Popular performance \& Construction of Social reality in Post- Amin Uganda'. Journal of Popular Culture, 32(2), Academic Research Library.

22. Breitinger, E. (Ed.) (2000). Uganda: A Cultural Landscape, Kampala: Fountain Publishers.

23. Schanker, H. Harry., \& Ommanney, Katharine, A. (1989). The Stage and the School, New York: MacGraw Hill.

24. Schechner, R. (1989). Between Theatre and Anthropology, Philadelphia: University of Pennsylvania Press.

25. Brocket, O.G. (1991). History of the Theatre. Boston: Allyn and Bacon.

26. Wilson, E. (1988). The Theatre Experience, New York: McGraw Hill Book Co.

27. Kamanyi, J., A. (1978). Comparative Study of Theatre Productions in Uganda Today, 
Unpublished MA Dissertation, Kampala: Makakere University.

28. Kasule, S. (1985). Theatre Development in Uganda, Unpublished MA Dissertation, Leeds: Leeds University.

29. Welton, M. (2004). 'Against Inclusivity: A Happy Hearsay about Theory \& Practice', NTQ, 19 (4).

30. Stanislavski, C. (1961). Creating a Role,(trans.), Elizabeth Reynolds Hapgood, New York: Theatre Arts books.

31. Carlson, M. (1993). Theories of the Theatre: A Historical and Critical Survey from the Greeks to the Present. London: Cornell University Press.

32. Festinger, L. (1957). A Theory of Cognitive Dissonance. Evanston, IL: Row \& Peterson.

33. Scott, K. (1975). In Search of African Theatre, New York: Charles Scribners and Sons.

34. Assisi, F. (2018). 'Labourers, Craftsmen and Artists', http:// htmlgear.tripod.com/ text, retrieved on $29^{\text {th }}$ December, 2018.

35. Antohin, A. (2018). 'Biomechanics: Theory for Method Actors: Acting, Directing, Theory', http://afronord.tripod.com/biomx, retrieved on $29^{\text {th }}$ December, 2018.

36. O'Farrell, L. (1994). Education and the Art of Drama, Geelong: Deakin University.
37. Ocwinyo, J. (2002). The unfulfilled dream. Fountain Pub Ltd.

38. Meyerick, J. (2003). 'The limits of Theory: Academic versus Professional Understanding of Theatre Problems', New Theatre Quarterly (NTQ), 19(3). Cambridge: Cambridge University Press.

39. The Monitor. (2006). 'Music is her passion' Saturday, April 08, 2006.

40. Tennyson, R.D., \& Cocchiarella, M.J. (1986). “An Empirically Based Instructional Design Theory for Teaching Concepts". Review of Educational Research, 56(1); 40-71.

41. Merrill, M.D., \& Tennyson, R.D. (1977). Concept Teaching: An Instructional Design Guide. Englewood Cliffs, NJ: Educational Technology.

42. Klausmeier, H. J., Ghatala, E. S., \& Prayer, D. A. (1974). Conceptual Learning and Development. NY: Academic Press.

43. Brocket, O. G. (1979). The Theatre: An Introduction. Chicago: Halt, Reinhard and Winston inc.

44. Crow, B. (2002). "African Metatheatre: Criticising Society, Celebrating the Stage". Research in African Literatures. Spring, 33(1), Academic Research Library. 